\title{
Research on Meshing Stiffness and Vibration Response of Pitting Fault Gears with Different Degrees
}

\author{
Jie Liu (D), Chengye Wang, and Wenchao Wu \\ School of Mechanical Engineering, Shenyang University of Technology, 110870, China \\ Correspondence should be addressed to Jie Liu; starliujie@126.com
}

Received 30 September 2019; Accepted 10 January 2020; Published 1 February 2020

Academic Editor: Hyeong Joon Ahn

Copyright ( 2020 Jie Liu et al. This is an open access article distributed under the Creative Commons Attribution License, which permits unrestricted use, distribution, and reproduction in any medium, provided the original work is properly cited.

\begin{abstract}
In order to study the influence of pitting on meshing stiffness, the normal distribution function is used to simulate the pitting location of pitting gear, and the potential energy method is used to analyze the influence of pitting on meshing stiffness. At the same time, the meshing stiffness of pitting gears with different degrees is analyzed by finite element method, and the validity of the calculation results with potential energy method is verified. On the basis of meshing stiffness, the dynamic model of gear system is established, and the vibration response of pitting gear system with different degrees is analyzed. The results show that with the increase of pitting area, the meshing stiffness decreases; the closer the meshing area of the driving wheel is to the pitting line, the more the meshing stiffness decreases, resulting in the intensification of vibration response and periodic impact; and in the time history diagram, there is a small spurious frequencies near the meshing frequency; in the phase diagrams and the Poincare diagram, trajectory and discrete point aggregation area is gradually increased.
\end{abstract}

\section{Introduction}

Gear transmission systems are widely used in many industrial application such as automobiles, planes, and wind power generators. In the process of gear meshing, pitting is easy to occur because of friction between tooth surfaces, so pitting fault is the most common form of gear failure. When the pitting occurs on the tooth surface of the gear, the effective contact area is less, which reduces the bearing capacity of the gear transmission system. At the same time, when pitting fault occurs on the surface of gear teeth, the gear teeth will be deformed, the meshing stiffness of the gear will change with the deformation of the gear teeth, and the gear transmission system is more likely to produce vibration in the working process, resulting in vibration and noise problems of the system, affecting the teeth. It has a great significance to study the transmission characteristics of the gear with pitting fault.

At present, many scholars have studied the pitting fault of gears. Zhang et al. [1] used the finite element method to carry out a static analysis of the planetary gear system. The research results play a certain role in the study of gear meshing characteristics. Wang et al. [2] calculate the meshing stiffness of the gear. It has made a foundation for the study of meshing stiffness of gear with pitting defects. Tan et al. [3] used acoustic emission (AE) technology to research pitting fault of spur gears. It was found that the pitting is more likely to occur near the pitting line on the tooth surface of spur gears. This research result has a great significance to the study of pitting location in the meshing stiffness of the pitting gear. Liang et al. [4] calculated the meshing stiffness of pitting gears with different degrees by potential energy method. Compared with the finite element method, the potential energy method is more accurate and reliable. Lei et al. [5] used the normal distribution theory to simulate the pitting location; they also used potential energy method to solve the meshing stiffness and analyzed the influence of pitting on gear meshing stiffness. Because the pitting pit distribution is more random, the research results are more in line with the actual working condition.

Zhang et al. [6] established the mathematical model of the nonlinear translational torsion of spur gears using the 
Lagrange equation and analyzed the meshing stiffness and vibration characteristics of gears and their transmission system based on gearbox. Shihua et al. [7] established an 8degree-of-freedom nonlinear spur gear rotor bearing model which included backlash, transmission error, eccentricity, gravity, and torque and studied its coupled transverse torsional vibration characteristics. Wu et al. [8] calculated the meshing stiffness of gears with different depth cracks by potential energy method and analyzed the influence of different depth cracks on the vibration response of gears.

In summary, there are many achievements in the research of meshing stiffness of gears. When many scholars study the influence of pitting on meshing stiffness and other characteristics of gears, the distribution of pitting fault is simulated regularly. However, according the actual engineering situation, the distribution of pitting fault is mostly random. In this paper, we use the normal distribution function to simulate the pitting of different degrees of pitting gears. In order to make the results more obvious, the pitting area difference between pitting gears with different degrees simulated in this paper is more, and the total pitting area difference is larger. At present, the research on the vibration mechanism of a fault gear is mostly confined to crack fault, but the pitting fault is more common in engineering practice, so this paper uses the meshing stiffness of pitting gear to analyze the vibration characteristics of the pitting gear system with different degrees of freedom.

\section{Model Formulation for Tooth Pitting and Meshing Stiffness Calculation}

2.1. Meshing Stiffness for Healthy Gears. The potential energy method has been widely used for calculation of meshing stiffness. In this paper, we utilize this method for evaluating the meshing stiffness and simulating the gear tooth as a cantilever beam starting from the root circle, as shown in Figure 1 . Since this study only take the linear elastic deflection into account in the meshing stiffness calculation, the other factors such as the correction of fillet-foundation stiffness [9], Hertzian contact [10], and transmission errors [11] are ignored.

For a pair of spur gears with contact ratio between the driving gear and the driven gear, according to the potential energy method $[8,12-14]$, the total mesh stiffness $k$ of a pair of spur gears can be expressed as follows:

$$
k=\frac{1}{1 / k_{\mathrm{h}}+1 / k_{\mathrm{b}_{1}}+1 / k_{\mathrm{a}_{1}}+1 / k_{\mathrm{s}_{1}}+1 / k_{\mathrm{f}_{1}}+1 / k_{\mathrm{b}_{2}}+1 / k_{\mathrm{a}_{2}}+1 / k_{\mathrm{s}_{2}}+1 / k_{\mathrm{f}_{2}}},
$$

where $k_{\mathrm{h}}, k_{\mathrm{b}}, k_{\mathrm{a}}$, and $k_{\mathrm{s}}$ are the Hertzian contact, bending, axial compressive, and shear stiffness, respectively, and $k_{\mathrm{f}}$ is the stiffness due to the fillet-foundation deflection; subscripts 1 and 2 indicate the driving and driven gear.

According to the cantilever beam theory of material mechanics and combined with Figure 1, the five parts of

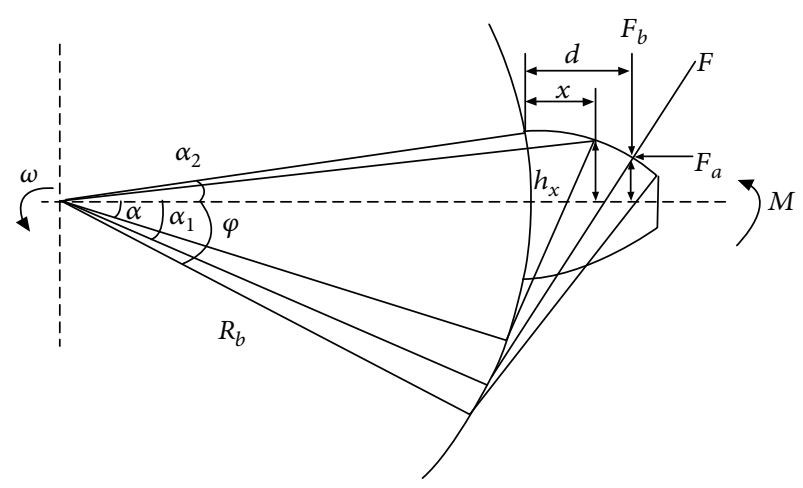

Figure 1: Cantilever beam model for the gear tooth.

the stiffness for gear: $k_{\mathrm{h}}, k_{\mathrm{b}}, k_{\mathrm{a}}, k_{\mathrm{s}}$, and $k_{\mathrm{f}}$ can be calculated as follows:

$$
\begin{aligned}
k_{\mathrm{h}} & =\frac{\pi E L}{4\left(1-v^{2}\right)}, \\
k_{\mathrm{b}} & =\frac{F^{2}}{2 U_{\mathrm{b}}}, k_{\mathrm{a}}=\frac{F^{2}}{2 U_{\mathrm{a}}}, k_{\mathrm{s}}=\frac{F^{2}}{2 U_{\mathrm{s}}}, \\
\frac{1}{k_{\mathrm{f}}} & =\frac{\cos ^{2} \alpha}{E L}\left\{L^{*}\left[\frac{u_{\mathrm{f}}}{s_{\mathrm{f}}}\right]^{2}+M^{*}\left[\frac{u_{\mathrm{f}}}{s_{\mathrm{f}}}\right]\right. \\
U_{\mathrm{b}} & =\int_{0}^{d} \frac{\left[F_{b}(d-x)-M\right]^{2}}{2 E I_{x}} d x, \\
U_{\mathrm{a}} & =\int_{0}^{d} \frac{F_{\mathrm{b}}^{2}}{2 E A_{x}} d x, \\
U_{\mathrm{s}} & =\int_{0}^{d} \frac{1.2 F_{\mathrm{b}}^{2}}{2 G A_{x}} d x,
\end{aligned}
$$$$
\frac{1}{k_{\mathrm{f}}}=\frac{\cos ^{2} \alpha}{E L}\left\{L^{*}\left[\frac{u_{\mathrm{f}}}{s_{\mathrm{f}}}\right]^{2}+M^{*}\left[\frac{u_{\mathrm{f}}}{s_{\mathrm{f}}}\right]^{2}+P^{*}\left(1+Q^{*} \tan ^{2} \alpha\right)\right\},
$$

where $L$ is the tooth width, $E$ is Young's modulus, $G$ is the shear modulus, $I_{x}$ and $A_{x}$ are the area moment of inertia and area of the section where the distance from the base circle is $x, \alpha$ is the gear pressure angle, $F$ is the force acting at the meshing point, $F_{\mathrm{a}}$ and $F_{\mathrm{b}}$ are the components of $F$, the specific direction is shown in Figure 1.

From Equations (3)-(7), the bending stiffness, axial compression stiffness, and shear stiffness can be deduced as follows:

$$
\frac{1}{k_{\mathrm{b}}}=\int_{-\alpha_{1}}^{\alpha_{2}} \frac{3\left\{1+\cos \alpha_{1}\left[\left(\alpha_{2}-\alpha\right) \sin \alpha-\cos \alpha\right]\right\}^{2}\left(\alpha_{2}-\alpha\right) \cos \alpha}{2 E L\left[\sin \alpha+\left(\alpha_{2}-\alpha\right) \cos \alpha\right]^{3}} d \alpha,
$$

$\frac{1}{k_{\mathrm{a}}}=\int_{-\alpha_{1}}^{\alpha_{2}} \frac{\left(\alpha_{2}-\alpha\right) \cos \alpha \sin ^{2} \alpha_{1}}{2 E L\left[\sin \alpha+\left(\alpha_{2}-\alpha\right) \cos \alpha\right]} d \alpha$,

$\frac{1}{k_{\mathrm{s}}}=\int_{-\alpha_{1}}^{\alpha_{2}} \frac{1 \cdot 2(1+v)\left(\alpha_{2}-\alpha\right) \cos \alpha \cos ^{2} \alpha_{1}}{E L\left[\sin \alpha+\left(\alpha_{2}-\alpha\right) \cos \alpha\right]} d \alpha$. 
TABLE 1: Basic parameters of gear pair.

\begin{tabular}{lcc}
\hline Parameters & Driving gear & Driven gear \\
\hline Tooth number & 55 & 75 \\
Young's modulus $(\mathrm{Pa})$ & $2.12 \times 10^{11}$ \\
Poisson's ratio $(\mathrm{v})$ & 0.29 \\
Module $(\mathrm{mm})$ & 2 \\
Width of teeth $L(\mathrm{~mm})$ & 20 \\
Addendum coefficient & 1 \\
Tip clearance coefficient & 0.25 \\
Pressure angle on the pitch circle $\alpha\left(^{\circ}\right)$ & 20 \\
\hline
\end{tabular}

2.2. Modeling of Tooth Pitting. According to the mechanism of pitting and the characteristics of gear movement, pitting usually occurs near the pitch line, and the pitting location should be randomly distributed in theory. From the practical experience of production, it can be seen that the pitting location is uniformly distributed along the direction of tooth width and normal distribution along the direction of tooth profile. In this paper, the pitting location of spur gears tooth width is modeled by normal distribution function, and the pitting pit distribution along the tooth profile is described by normal distribution function.

The gear parameters are shown in Table 1. The pitting location on the gear tooth is modeled as a two-dimensional random variable in this study. If we set the coordinates of the pitting pit on the gear teeth as $\left(x_{i}, y_{i}\right)$, the $x$ direction is the profile direction of the gear teeth, and the $y$ direction is the width direction, the following are the relationship between $x_{i}$ and $y_{i}$.

$$
\begin{aligned}
& x_{i} \sim N\left(\mu, \sigma^{2}\right), \\
& y_{i} \sim U(0, L) .
\end{aligned}
$$

Besides, for the normal distribution function in Equation (11), the $3 \sigma$ criterion is used to describe the distribution areas of pits in this study, which means that in the direction of tooth height, $99.73 \%$ of the pits appear in the field of $\mu-3 \sigma \leq x_{i} \leq \mu+3 \sigma$. Therefore, $\mu$ and $\sigma$ can be calculated as follows:

$$
\mu=x_{p}-\delta, \sigma=\frac{x_{p}-x_{\min }-\delta}{3},
$$

where $x_{p}$ is the coordinate value of the pitch circle in the $x$ direction, $x_{\min }$ is determined by the boundary of the meshing area, and $\delta$ is the distance between the mean line of normal distribution and the pitch line, as shown in Figure 2.

In this paper, pitting pits are simulated as spherical pits, and three pitting pit levels are defined: Level 1, Level 2, and Level 3. The radius of Level 1 pits is $0.35 \mathrm{~mm}$, while it is $0.45 \mathrm{~mm}$ in Level 2 and $0.55 \mathrm{~mm}$ in Levels 3 . We simulated

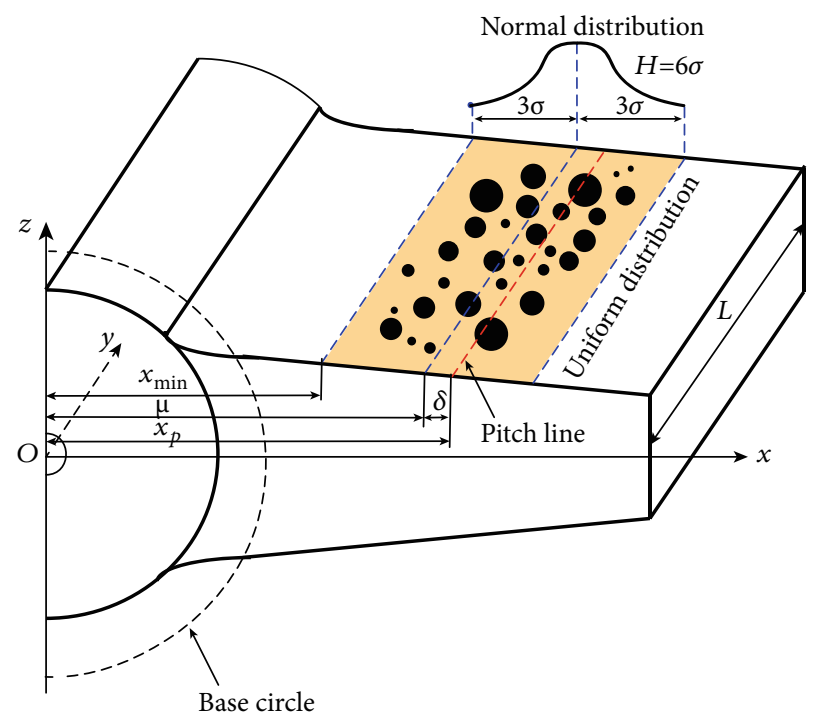

FIGURE 2: Distribution of pits on the tooth surface.

three degrees of pitting models. Figure 3 gives the schematic of the three degrees of the pitting gear. The definitions of the three pitting degrees are illustrated below:

Degree 1: 20 Level 1 pitting pits are distributed on the surface of the gear teeth, with a normal distribution along the tooth profile direction and a uniform distribution along the tooth width direction. The pitting area accounts for $8.552 \%$ of the gear tooth surface area.

Degree 2: 20 Level 1 pitting pits and 15 Level 2 pitting pits are distributed on the surface of the gear teeth, with the same distribution as Degree 1. The pitting area accounts for $19.155 \%$ of the gear tooth surface area.

Degree 3: 20 Level 1 pitting pits, 15 Level 2 pitting pits, and 12 Level 3 pitting pits are distributed on the surface of the gear teeth, with the same distribution as Degree 1. The pitting area accounts for $31.826 \%$ of the gear tooth surface area.

2.3. Meshing Stiffness for Pitting Gears. With the pitting occurring on the tooth surface, the effective contact length during meshing is decreased. From Equations (2)-(7), it can be seen that the contact length during meshing has a large influence on the evaluation of the potential energy as well as the meshing stiffness of gears. So, the Hertzian contact stiffness, axial compression stiffness, bending stiffness, and shear stiffness all change with pitting.

In this paper, we assume that the tooth contact line consists of $N$ pixel points, illustrated as the red line in Figure 2. For each single pixel points, we use a special color to illustrate whether this point represents healthy and pitting. More concretely, if this pixel point is in the nonpitting area, it is set to be white; if this pixel point is in the pitting area, it is set to be black. Finally, if the number of black pixels is $\Delta N$. The decreased tooth contact line length would be expressed as $\Delta L=(\Delta N / N) \times L$. 


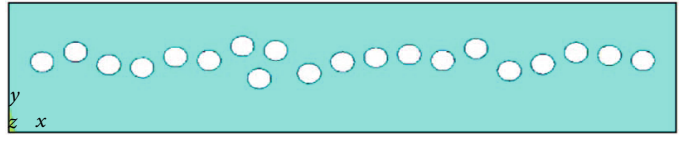

(a)

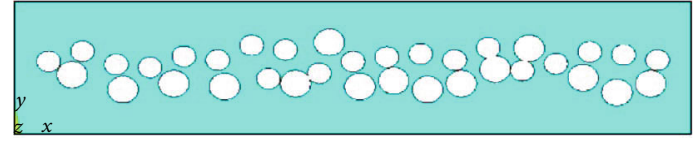

(b)

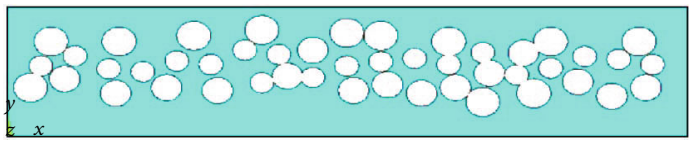

(c)

Figure 3: Simulation of three pitting degrees. (a) Degree . (b) Degree 2. (c) Degree 3.

Then, the Hertz stiffness, bending stiffness, shear stiffness, and axial compression stiffness for pitting gear can be calculated as follows:

$$
k_{\mathrm{h}}=\frac{\pi E(L-\Delta L)}{4\left(1-v^{2}\right)},
$$

$$
\begin{aligned}
\frac{1}{k_{\mathrm{b}}}= & \int_{-\alpha_{1}}^{\alpha_{2}} \frac{3\left\{1+\cos \alpha_{1}\left[\left(\alpha_{2}-\alpha\right) \sin \alpha-\cos \alpha\right]\right\}^{2}\left(\alpha_{2}-\alpha\right) \cos \alpha}{2 E L\left[\sin \alpha+\left(\alpha_{2}-\alpha\right) \cos \alpha\right]^{3}} d \alpha \\
& -\int_{-\alpha_{1}}^{\alpha_{2}} \frac{3 \Delta L\left\{1+\cos \alpha_{1}\left[\left(\alpha_{2}-\alpha\right) \sin \alpha-\cos \alpha\right]\right\}^{2}\left(\alpha_{2}-\alpha\right) \cos \alpha}{2 E L^{2}\left[\sin \alpha+\left(\alpha_{2}-\alpha\right) \cos \alpha\right]^{3}} d \alpha \\
& +\int_{-\alpha_{1}}^{\alpha_{2}} \frac{3 \Delta L\left\{1+\cos \alpha_{1}\left[\left(\alpha_{2}-\alpha\right) \sin \alpha-\cos \alpha\right]\right\}^{2}\left(\alpha_{2}-\alpha\right) \cos \alpha}{2 E L^{2}\left[\sin \alpha+\left(\alpha_{2}-\alpha\right) \cos \alpha-\left(t_{i} / 2 R_{\mathrm{b}}\right)\right]^{3}} d \alpha \\
& +\int_{0}^{x_{\mathrm{b}}-x_{r}} \frac{3\left[R_{\mathrm{b}}-R_{\mathrm{b}} \cos \alpha_{1} \cos \alpha_{2}+x_{1} \cos \alpha_{1}\right]^{2}}{2 E L h_{x_{1}}^{3}} d x_{1},
\end{aligned}
$$

$$
\begin{aligned}
\frac{1}{k_{\mathrm{s}}}= & \int_{-\alpha_{1}}^{\alpha_{2}} \frac{1.2(1+v)\left(\alpha_{2}-\alpha\right) \cos \alpha \cos ^{2} \alpha_{1}}{E L\left[\sin \alpha+\left(\alpha_{2}-\alpha\right) \cos \alpha\right]} d \alpha \\
& -\int_{-\alpha_{1}}^{\alpha_{2}} \frac{1.2 \Delta L(1+v)\left(\alpha_{2}-\alpha\right) \cos \alpha \cos ^{2} \alpha_{1}}{E L^{2}\left[\sin \alpha+\left(\alpha_{2}-\alpha\right) \cos \alpha\right]} d \alpha \\
& +\int_{-\alpha_{1}}^{\alpha_{2}} \frac{1.2 \Delta L(1+v)\left(\alpha_{2}-\alpha\right) \cos \alpha \cos ^{2} \alpha_{1}}{E L^{2}\left[\sin \alpha+\left(\alpha_{2}-\alpha\right) \cos \alpha-\left(t_{i} / 2 R_{\mathrm{b}}\right)\right]} d \alpha \\
& +\int_{0}^{x_{\mathrm{b}}-x_{r}} \frac{1.2(1+v) \cos ^{2} \alpha_{1}}{E L h_{x_{1}}} d \alpha,
\end{aligned}
$$$$
\frac{1}{k_{a}}=\int_{-\alpha_{1}}^{\alpha_{2}} \frac{\left(\alpha_{2}-\alpha\right) \cos \alpha \sin ^{2} \alpha_{1}}{2 E L\left[\sin \alpha+\left(\alpha_{2}-\alpha\right) \cos \alpha\right]} d \alpha
$$$$
-\int_{-\alpha_{1}}^{\alpha_{2}} \frac{\Delta L\left(\alpha_{2}-\alpha\right) \cos \alpha \sin ^{2} \alpha_{1}}{2 E L^{2}\left[\sin \alpha+\left(\alpha_{2}-\alpha\right) \cos \alpha\right]} d \alpha
$$$$
+\int_{-\alpha_{1}}^{\alpha_{2}} \frac{\Delta L\left(\alpha_{2}-\alpha\right) \cos \alpha \sin ^{2} \alpha_{1}}{2 E L^{2}\left[\sin \alpha+\left(\alpha_{2}-\alpha\right) \cos \alpha-\left(t_{i} / 2 R_{\mathrm{b}}\right)\right]} d \alpha
$$$$
+\int_{0}^{x_{\mathrm{b}}-x_{r}} \frac{\sin ^{2} \alpha_{1}}{2 E L h_{x_{1}}} d x_{1} \text {, }
$$

where $t_{i}$ is the depth of pits in the $i$ th level of severity. With the expressions of the mesh stiffness provided above, we can calculate the meshing stiffness under different pitting degree. The meshing stiffness results of healthy and different degrees of pitting gears are illustrated in Figure 4.

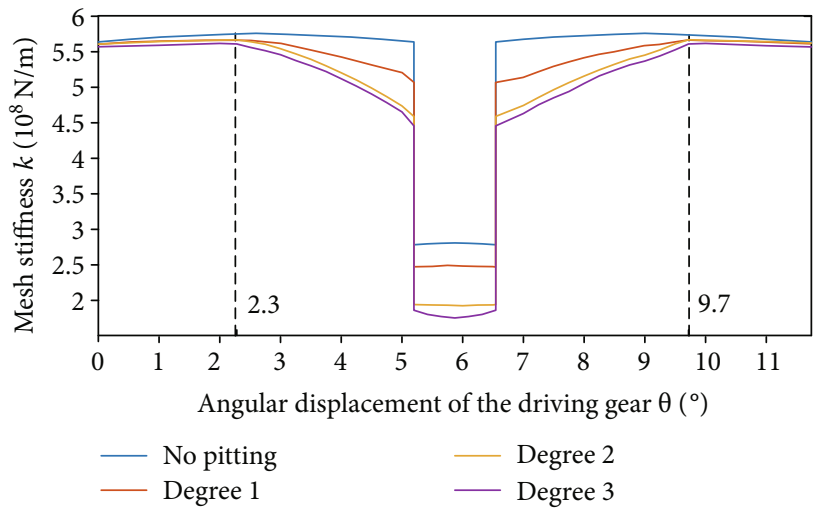

Figure 4: Meshing stiffness of pitting gear with different degrees.

TABLE 2: Mesh stiffness drop percentage.

\begin{tabular}{lcc}
\hline Degree & Double tooth & Single tooth \\
\hline 1 & $11.53 \%$ & $11.92 \%$ \\
2 & $17.55 \%$ & $25.25 \%$ \\
3 & $22.15 \%$ & $37.13 \%$ \\
\hline
\end{tabular}

From Figure 4, it can be seen that the gear rotation angle is between $2.3^{\circ}$ and $9.7^{\circ}$, and the meshing stiffness changes obviously. The larger the pitting area is, the more obvious meshing stiffness decrease. The percentage of each stage drop is illustrated in Table 2. From Figure 4 and Table 2, it can be seen that the closer the meshing area is to the gear pitch line, the lower the meshing stiffness value is. And the reduction ratio of meshing stiffness in single-tooth-pair meshing duration is more obvious than that in double-tooth-pair meshing duration. Because the pitting pit distribution is normal distribution, there are more pitting pits and larger pitting area in the middle of the gear tooth surface near the pitch line. The meshing near the pitch line is more easily worn, and the pitting fault area is larger than the other parts of the tooth surface; that is the reason why the meshing stiffness value is lower when the meshing area near the pitch line.

2.4. Validation of Meshing Stiffness by FEM. Because of the finite element method has been approved by many scholars, we use this method to valid the meshing stiffness evaluation result; the model built by FEM is shown in Figure 5 . 


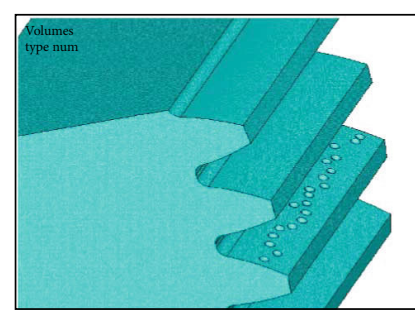

(a)

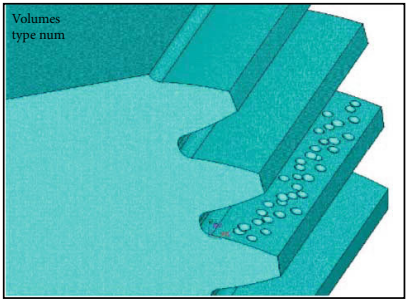

(b)

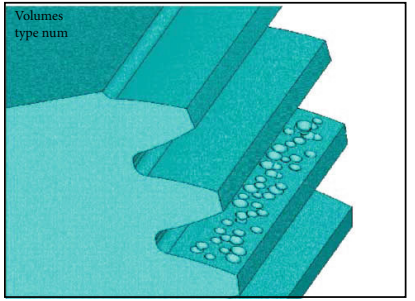

(c)

FIGURE 5: Different pitting gear FEM models. (a) Degree 1 pitting gear model. (b) Degree 2 pitting gear model. (c) Degree 3 pitting gear model.

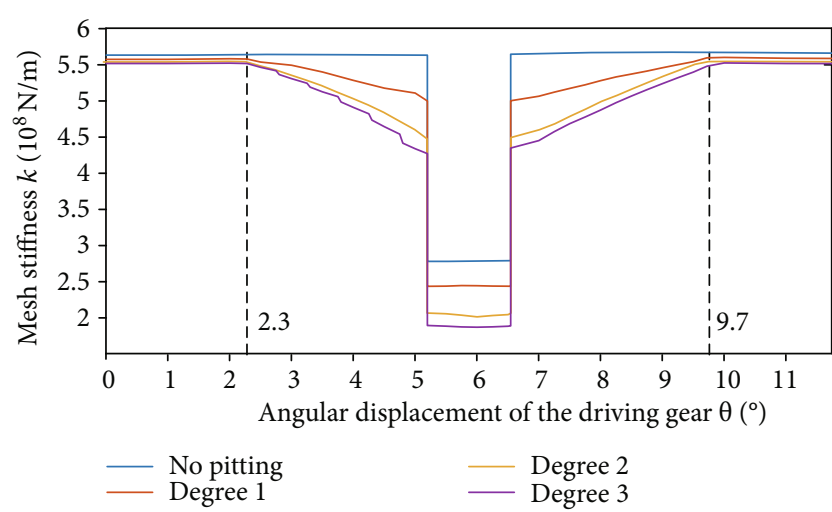

Figure 6: Meshing stiffness of pitting gear with different degrees calculated by the FEM method.

Meanwhile, we simulate the transmission process of this pair of gears in a meshing period and apply $T=60 \mathrm{Nm}$ torque to analyze the meshing stiffness of healthy and pitting gears. The results are illustrated in Figure 6.

Comparing Figure 4 with Figure 6, it can be seen that the meshing stiffness values of pitting gears with different degrees evaluated by these two methods are basically close to each other. The meshing stiffness calculated by potential energy method is slightly less than FEM, and Figure 4 shows a relatively smooth meshing stiffness curve compared with Figure 6. Because compared with the finite element method, the results by potential energy method is more accurate. From the comparison, we can find that there is only a little difference between the two methods in meshing stiffness value, so it can be recognized that the meshing stiffness obtained by the potential energy method is reliable.

\section{Research of Pitting Gear Vibration Response}

In this section, we use the lumped parameter method to analyze the vibration response of pitting gear meshing stiffness in different degrees, assuming that there is no error in gear meshing, and the mass and inertia of the shaft are concentrated on the gear without considering the friction between the gears and the resonance of the gearbox. In order to analyze the influence of meshing stiffness of gear with pitting

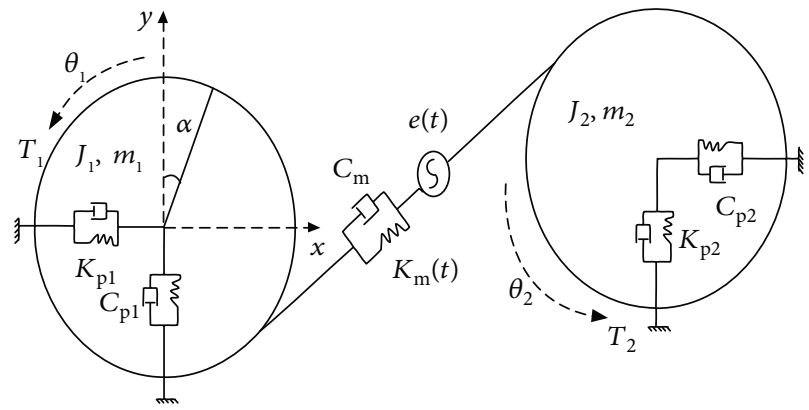

FIgURe 7: Gear system dynamics model.

TABLE 3: Dynamic model parameters of gear system.

\begin{tabular}{lcc}
\hline Parameters & Driving gear & Driven gear \\
\hline Moment of inertia & 0.041 & 0.079 \\
Mass $(\mathrm{kg})$ & 1.53 & 3.01 \\
Torsional stiffness of shaft $\left(\mathrm{N} \mathrm{m}^{-1}\right)$ & \multicolumn{2}{c}{$2 \times 10^{8}$} \\
Torsional damping $\left(\mathrm{N} \mathrm{S} \mathrm{m}^{-1}\right)$ & \multicolumn{2}{c}{1800} \\
Lateral damping $\left(\mathrm{N} \mathrm{S} \mathrm{m}^{-1}\right)$ & \multicolumn{2}{c}{2000} \\
Backlash $(\mathrm{mm})$ & \multicolumn{2}{c}{$1 \times 10^{-5}$} \\
\hline
\end{tabular}

fault on vibration response, a 6-DOF gear system dynamics model is established, as shown in Figure 7.

$$
\left\{\begin{array}{l}
m_{1} \ddot{x}_{1}+C_{p_{1}} \dot{x}_{1}+K_{p_{1}} x_{1}=-F_{m} \sin \alpha, \\
m_{1} \ddot{y}_{1}+C_{p_{1}} \dot{y}_{1}+K_{p_{1}} y_{1}=-m_{1} g+F_{m} \cos \alpha, \\
J_{1} \ddot{\theta}_{1}=T_{1}-F_{m} r_{1}, \\
m_{2} \ddot{x}_{2}+C_{p_{2}} \dot{x}_{2}+K_{p_{2}} x_{2}=F_{m} \sin \alpha, \\
m_{2} \ddot{y}_{2}+C_{p_{2}} \dot{y}_{2}+K_{p_{2}} y_{2}=-m_{2} g+F_{m} \cos \alpha, \\
J_{2} \ddot{\theta}_{2}=T_{2}-F_{m} r_{2},
\end{array}\right.
$$

where $m$ is the mass of gear, $J$ is the moment of inertia, $K_{p}$ is the bearing support stiffness, $C_{p}$ is the damping coefficients, $T$ is the gears torque, $\alpha$ is pressure angle, $\theta$ is angular displacements in the $x$ and $y$ directions of gears, and the subscripts 1 and 2 indicate the driving and driven gear. 

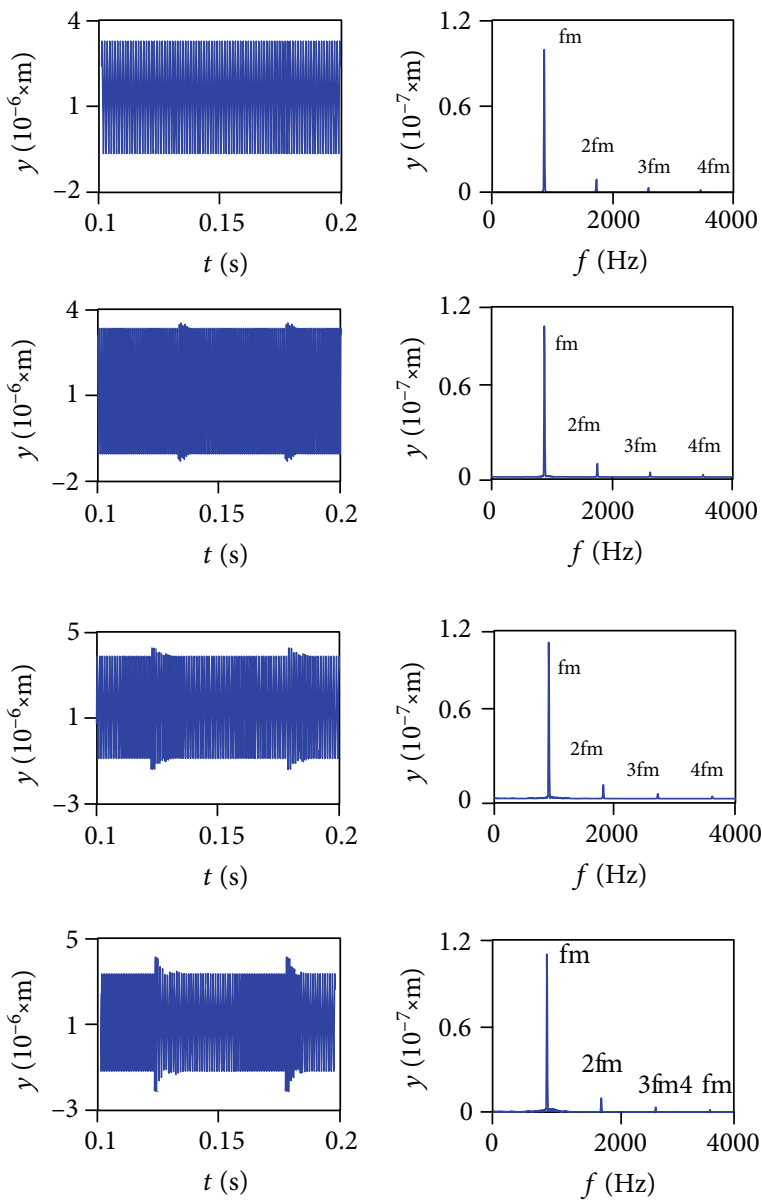

(a) (b)
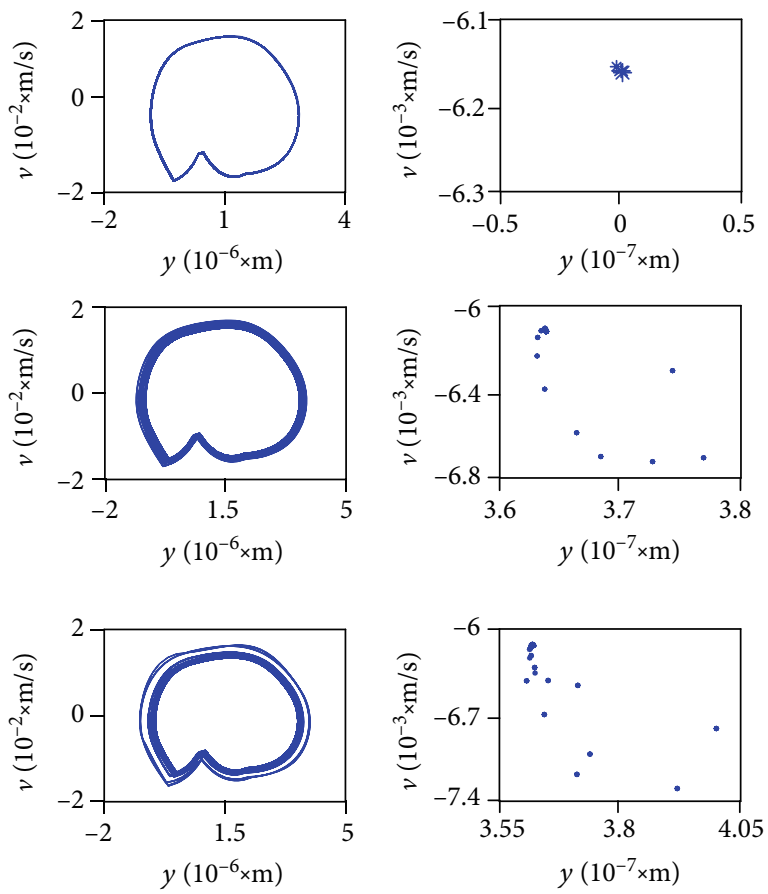

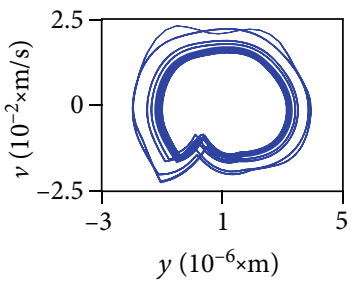

(c)

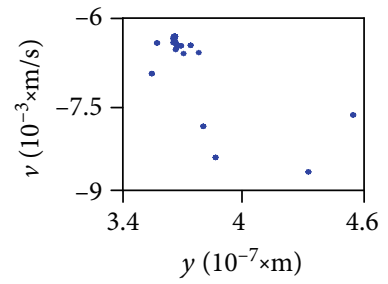

(d)

FIGURE 8: Vibration response of gear system with different pitting. (a) Time history. (b) FFT spectra. (c) Phase planes. (d) Poincare maps.

The time-varying meshing force $F_{m}$ of the gear system can be expressed as

$$
F_{m}(t)=c_{m} \dot{\delta}+k_{m}(t) f(\delta)
$$

where $c_{m}$ is the meshing damping of gears, $k_{\mathrm{m}}(t)$ is the timevarying meshing stiffness, and $\delta$ is the relative displacement of gears along the meshing line, which can be expressed as

$$
\begin{aligned}
\delta= & x_{1} \sin \alpha+y_{1} \cos \alpha+r_{1} \theta_{1}-x_{2} \sin \alpha \\
& +y_{2} \cos \alpha+r_{2} \theta_{2}+e(t),
\end{aligned}
$$

where $e(t)$ is the transmission error for the gear.

$f(\delta)$ is a nonlinear function of gap, which can be expressed as

$$
f(\delta)=\left\{\begin{array}{lc}
\delta-b & (\delta>b), \\
0 & (-\mathrm{b} \leq \delta \leq b), \\
\delta+b & (\delta<-b),
\end{array}\right.
$$

where $b$ is the gear backlash. The dynamic model parameters of gear system are shown in Table 3. According to Table 3 and the previously calculated meshing stiffness, we use the Runge-Kutta iteration to solve the gear dynamic equation and analyze the vibration response of pitting fault in different degrees, the results are shown in Figure 8.

From Figure 8(a), it can be seen that the vibration amplitude of healthy gears is relatively stable. When pitting occurs on the tooth surface of gears and the pitting area become larger and larger, the vibration amplitude will be increased and the amplitude will be unstable. From Figure 8(b), it can be seen that the meshing frequency $f_{\mathrm{m}}$ is the dominant response in healthy gears and there are $2 f_{\mathrm{m}}, 3 f_{\mathrm{m}}$, and $4 f_{\mathrm{m}}$. When pitting occurs on the tooth surface of the gear, a small spurious frequency is generated near $f_{\mathrm{m}}$ and $2 f_{\mathrm{m}}$, and the spurious frequency increases with the pitting degree increasing. The position of $3 f_{\mathrm{m}}$ and $4 f_{\mathrm{m}}$ approached the high-frequency position with the increase of pitting area. From Figure 8(c), it can be seen that the track of phase diagram of a healthy gear is regular. When the pitting occurs on the tooth surface, the track of phase diagram becomes wider with the increase of pitting area, and the cross track occurs when pitting degree is in Degrees 2 and 3, which Degrees 2 and 3 is moderate and severe degree, respectively. From Figure $8(\mathrm{~d})$, it can be seen that all discrete points of the healthy gear system in Poincare diagram gather in one 
region, and the discrete points become larger when the pitting fault occurs.

\section{Conclusions}

In this paper, we could find that the larger the pitting area of the gear, the lower the meshing stiffness of the gear. As the gear rotates, the meshing stiffness decreases obviously when the pitting area enters the meshing area. The closer the meshing area of the driving gear is to the pitch line, the more the meshing stiffness decreases. The meshing stiffness calculated by finite element method is close to that calculated by potential energy method. Under healthy conditions, the average meshing stiffness of single-tooth-pair meshing duration calculated by potential energy method is $2.7 \times 10^{8} \mathrm{~N} / \mathrm{m}^{-1}$ and that of double-tooth-pair is $5.56 \times 10^{8} \mathrm{~N} / \mathrm{m}^{-1}$. The average meshing stiffness of single-tooth-pair calculated by finite element method is $2.84 \times 10^{8} \mathrm{~N} / \mathrm{m}^{-1}$ and that of doubletooth-pair is $5.71 \times 10^{8} \mathrm{~N} / \mathrm{m}^{-1}$; the average difference of meshing stiffness of single-tooth-pair is $4.9 \%$ and that of double-tooth-pair is $2.6 \%$. Compared with ISO standard, potential energy method is more accurate.

Through the dynamic analysis of pitting gear, it can be seen that when the gear teeth with pitting is meshing, the vibration impact is caused by the reduction of meshing stiffness of the gear. With the increase of pitting area, the meshing stiffness decreases, the vibration amplitude increases, the clutter frequency increases gradually in frequency domain, the trajectory width increases gradually in the phase diagram and the intersection trajectory occurs, and the scattered point aggregation area in Poincare diagram increases gradually. The research results of this paper lay a foundation for further fault diagnosis.

\section{Data Availability}

All data used to support the findings of this study are included within the article. If the researchers are interested in obtaining the numerical solution files, please contact email address: starliujie@126.com.

\section{Conflicts of Interest}

No potential conflicts in this paper is declared by the authors about research, relationship and publication.

\section{Acknowledgments}

Fund program of supporting this article: Natural Science Foundation of China (No. 51675350).

\section{References}

[1] Z. Shuangwei, Y. Wenjun, J. Liang, and W. Haozhen, "Analysis of gear meshing stiffness based on Finite Element Method," Heilongjiang Science and Technology Information, vol. 24, pp. 114-115, 2016.

[2] J. Wang and I. Howard, "The torsional stiffness of involute spur gears," Proceedings of the Institution of Mechanical
Engineers, Part C: Journal of Mechanical Engineering Science, vol. 218, no. 1, pp. 131-142, 2004.

[3] C. K. Tan, P. Irving, and D. Mba, "A comparative experimental study on the diagnostic and prognostic capabilities of acoustics emission, vibration and spectrometric oil analysis for spur gears," Mechanical Systems and Signal Processing, vol. 21, no. 1, pp. 208-233, 2007.

[4] X. Liang, H. Zhang, L. Liu, and M. J. Zuo, “The influence of tooth pitting on the mesh stiffness of a pair of external spur gears," Mechanism and Machine Theory, vol. 106, pp. 1-15, 2016.

[5] Y. Lei, Z. Liu, D. Wang, X. Yang, H. Liu, and J. Lin, “A probability distribution model of tooth pits for evaluating timevarying mesh stiffness of pitting gears," Mechanical Systems and Signal Processing, vol. 106, pp. 355-366, 2018.

[6] L. Zhang, C. Chen, J. Liu, and S. Zhao, "Dynamic characteristic of spur gear with flexible support of gearbox," Journal of Vibroengineering, vol. 20, no. 3, pp. 1530-1543, 2018.

[7] S. Zhou, G. Song, Z. Ren, and B. Wen, "Nonlinear dynamic analysis of coupled gear-rotor-bearing system with the effect of internal and external excitations," Chinese Journal of Mechanical Engineering, vol. 29, no. 2, pp. 281-292, 2016.

[8] S. Wu, M. J. Zuo, and A. Parey, "Simulation of spur gear dynamics and estimation of fault growth," Journal of Sound and vibration, vol. 317, no. 3-5, pp. 608-624, 2008.

[9] H. Ma, J. Zeng, R. Feng, X. Pang, and B. Wen, “An improved analytical method for mesh stiffness calculation of spur gears with tip relief," Mechanism and Machine Theory, vol. 98, pp. 64-80, 2016.

[10] H. Ma, J. Zeng, R. Feng, X. Pang, Q. Wang, and B. Wen, "Review on dynamics of cracked gear systems," Engineering Failure Analysis, vol. 55, pp. 224-245, 2015.

[11] D. K. Tse and H. H. Lin, "Separation distance and static transmission error of involute spur gears," in 28th Joint Propulsion Conference and Exhibit, Nashville, TN, U.S.A, July 1992.

[12] D. C. H. Yang and J. Y. Lin, "Hertzian damping, "Tooth friction and bending elasticity in gear impact dynamics"," Journal of Mechanisms, Transmissions, and Automation in Design, vol. 109, no. 2, pp. 189-196, 1987.

[13] X. Tian, Dynamic Simulation for System Response of Gearbox Including Localized Gear Faults, University of Alberta, 2005.

[14] Z. Chen, J. Zhang, W. Zhai, Y. Wang, and J. Liu, "Improved analytical methods for calculation of gear tooth filletfoundation stiffness with tooth root crack," Engineering Failure Analysis, vol. 82, pp. 72-81, 2017. 